\title{
PENSAR Y PODER
}

PENSAR E PODER

THINKING AND POWER

Juan David Zabala Sandoval ${ }^{1}$

${ }^{1}$ Universidad de Ibagué, Tolima, Colombia

\section{Reseña de}

Zemelman, H. (2012). Pensar y Poder: Razonar y gramática del pensar histórico. Chiapas, México: Siglo XXI Editores.

Pensar y poder, como ejercicios que enmarcan la autonomía y las posibilidades de determinación del propio sujeto a partir de su colocación histórica son hoy necesarios para sortear las coyunturas que aquejan a esta Latinoamérica, es reconocer en uno de sus autores contemporáneos más profundos una representación del pensamiento de nuestra tierra, Hugo Zemelman, chileno exiliado en México, como muchos tantos que tuvieron que salvaguardar su vida de dictaduras y autocracias que aún no cesan en el continente.

Este tex to del reconocido epistemólogo chileno Hugo Zemelman presenta algunas de las disquisiciones que el autor elaboró a lo largo de diferentes trabajos presentados en años anteriores referentes al sujeto y la capacidad que éste tiene de colocarse y experimentar el mundo conforme su devenir histórico, al igual que otro de sus libros, "El ángel de la historia: determinación y autonomía de la condición humana” (2007). Sin embargo, en esta ocasión no solo centró su interés en los procesos de subjetivación, en sus particularidades y condiciones, sino que presenta al lenguaje como elemento fundante no solo de la dimensión cognitiva del sujeto sino también de la capacidad simbólica que permite a éste entender el mundo, o mejor, ser-en y con el mundo.

Para ello divide el presente libro en seis capítulos a través de los cuales da cuenta de temas fundamentales para la estructuración de un enfoque epistemológico que propenda por la superación de la brecha entre el objeto y el sujeto existente en la mirada positivista y de carácter explicativo; así como también da cuenta de algunos temas relacionados como el uso político del lenguaje, la capacidad de enunciar, tan característica del sujeto y la relación entre pensamiento y existencia.

Es así que para el primer capítulo, denominado "Pensar histórico", el autor tiene la intención de plantear la construcción de conocimiento como proceso dialéctico que no se reduce simplemente a dar cuenta del objeto en cuanto a mediciones y funcionalidad, pues eso sería reducir a su mínima expresión tanto al objeto estudiado como al sujeto que lo estudia. De allí que proponga entender al objeto devenido históricamente; lo circunscribe en unas condiciones específicas que lo hicieron posible y que lo delimitan en la actualidad, 
lo que a su vez hace imposible entenderlo estático y solo en el presente. También resulta necesario cambiar la concepción del sujeto, no solo como quien mira el mundo pasar, sino como aquel cuya experiencia particular es resultado de las condiciones que lo hacen posible, por lo tanto, el pensar histórico pasa por reconocer aquellas coordenadas del sujeto que le sirven como marcos de referencia (colectivos o particulares) que hacen posible la colocación del sujeto, como un ángulo que no es ajeno a la experiencia del mundo, sino que es en tanto experimenta (Zemelman, 2007). En últimas, el sujeto como ángulo constituido a partir de experiencias individuales y colectivas sedimentadas de forma histórica conforman la capacidad de despliegue del mismo, en tanto la capacidad de reconocer sus propios límites y con ello sus posibilidades de potenciación de sí.

Para el segundo capítulo, titulado "Orden y política”, el autor invita a abordar las implicaciones que a nivel político tendría el pensar la conformación del conocimiento desde un plano subjetivo, hermenéutico e histórico; que entre otras cosas, conlleva a repensar la relación entre individuo y Estado en términos de una autonomía de los sujetos que puede complejizar el establecimiento de un orden social. A su vez, el autor insta a considerar la política no como un campo de prácticas y estructuras cerradas sino como campo amplio para la construcción de "espacios de relaciones en los cuales el hombre encuentra aquello que pueda compartir” (2012, p. 63); en otras palabras, la dimensión política está necesariamente configurada y reconfigurada por la acción de los sujetos y el uso del lenguaje en la cotidianidad. Entonces, la forma en que se enuncien y se aborden (de forma explicativa o predictiva) los diferentes fenómenos, podría cerrar o abrir posibilidades de construcción de conocimiento así como formas de ser con, frente y/o en contra de otros.

Consecuente con lo anterior, en el capítulo "Identidad y apertura de posibilidades en el conocimiento", el epistemólogo trata de ahondar en la dialéctica implícita que se establece a lo largo del libro entre la capacidad de movimiento particular que subyace a la idea de la generación del conocimiento conforme juicios subjetivos y lo que parecería ser su antítesis, la determinación del conocimiento en tanto fenómeno, sujeto o relación, esto es, la categorización misma encierra una determinación y unos límites. De allí que la disputa que se entrevé en la identidad yace en la posibilidad que las determinaciones no sometan en su totalidad al movimiento, entendido también como reconocimiento y apertura de posibilidades de despliegue, sin que este diluya en su totalidad aquellas determinaciones desembocando en un relativismo enajenante. El pensador chileno propone entonces una óptica que entienda la tensión identidad-determinación a nivel histórico, esto es, como forma de abordar la supuesta linealidad pasado-presente-futuro dando cabida a otras interpretaciones posibles en tanto fuente de experiencia como apertura a múltiples y (al parecer) inacabables interpretaciones en tanto posibles concreciones de lo real que movilizan no solo al sujeto sino también a la identidad del que interpreta y de lo interpretado. "Lo anterior plantea no limitarse a la lógica de objetos, ya que debemos tener claro que el objeto es reflejo de un modo particular de concreción entre una diversidad posible de concreciones" (Zemelman, 2012, p. 88).

En "Capacidad de nombrar y espacio de autonomía”, el cuarto capítulo del libro, el autor vuelve a un tema que había quedado abierto en capítulos anteriores, a saber, la posibilidad de pensar la realidad desde el reconocimiento y la toma de distancia frente a los determinantes, de aquello invariante que permite situarse y darle prevalencia justamente a lo que sí varía, a aquello móvil. Esta es una preocupación permanente a lo largo de su obra, también evidente en su artículo "Sujeto y Subjetividad: la problemática de las 
alternativas como construcción posible”. Pues para Zemelman, el acto de pensar, entendido como la toma de distancia frente a lo inmediato e invariante; pensar sería entonces un acto de autonomía que conlleva a articular la historicidad de los determinantes del sujeto con su experiencia particular. Por lo cual, la búsqueda de autonomía pasa por el uso del lenguaje, que no es un uso funcional sino más bien es constituyente del sujeto mismo, "busca un lenguaje no sojuzgado al orden, que permita preservar su autonomía para cumplir con la función de significar el excedente de realidad que el orden-poder oculta" (Zemelman, 2012, p. 94).

Acto seguido, se presenta la argumentación correspondiente al "Desafío epistémico para la construcción de enunciados”, que básicamente yace en el reto de transformar el mundo percibido en tanto susceptible de cognición a partir de cambiar el uso del lenguaje, pues si el lenguaje es la base del pensamiento, entonces los procesos cognitivos también habrán de cambiar conjunto al lenguaje y con ellos la significación del mundo. Parece entonces necesario propender por la construcción de enunciados menos explicativos y denotativos que simplemente se limitan a la afirmación de contenido y la identificación de los objetos del mundo, en su lugar, habría de apostar por enunciados categóricos y comprensivos, lo que permitiría ampliar el razonamiento hacia otros horizontes que puedan ser enriquecidos por la intuición, la imaginación y la sensibilidad a partir de la inclusión del ángulo de enunciación propio del sujeto y su momento histórico, esto es, construir enunciados correspondientes a partir de una conciencia histórica y de un proceso de colocación propio al sujeto y sus determinantes. En últimas, la intención no solo es restar centralidad al objeto, devolviéndole capacidad de movimiento al sujeto, sino también ha de buscarse facilitar el reconocimiento de posibilidades (quizás de utopías) y la búsqueda estas, o su potenciación.

Por su parte, en el sexto capítulo, "Pensar y existencia”, se aborda la relación entre el acto de pensar, como forma de resistencia ante la inercia misma a la cual el ser humano se ve sometido en su cotidianeidad y el existir, no solamente como estar en el mundo como un cuerpo carente de reflexión y postura, sino como un ser que es a la vez que piensa el mundo y se piensa a sí mismo. Es entonces, a partir del pensar, que es posible hallar una fuente volitiva para no dejarse llevar por la inercia, por las facilidades del mundo ya estructurado, por lo dado y lo determinado, sino buscar un pensar crítico ante las condiciones contextuales que determinan su colocación y un pensar histórico ante sus prácticas y usos del lenguaje, para así darle movimiento al mundo construido a partir del conocimiento y de las relaciones que se estructuran con la construcción de enunciados no solo denotativos sino también contextuales e históricos.

El libro cierra con un texto complementario en el que se abordan y profundizan múltiples temas que a lo largo y amplio del libro no habían sido puntualizados apropiadamente, temas como algunas consideraciones generales para la investigación desde el enfoque hermenéutico, prácticas para el pensar histórico, para lograr conciencia de las posibilidades y de la capacidad de apertura epistémica, aclaraciones acerca de la construcción de preguntas y enunciados que comprendan los diferentes niveles (e.g. sintáctico, contextual e histórico), así como algunos aspectos problemáticos del enfoque del pensar histórico y del discurso de la potenciación.

En términos generales el texto resulta refrescante, pues propone un enfoque que intenta y en gran medida logra conectar la crítica elaborada a partir del enfoque históricosocial de la escuela de Frankfurt, con los estudios cognitivos, lingüísticos y pragmáticos 
acerca de la significación del mundo y de la creación de otros mundos posibles a partir del lenguaje y su uso cotidiano y científico. Además, el libro presenta de forma sintética una propuesta de una epistemología que busca superar la miopía (o mejor ceguera) positivista basada en el naturalismo, en la actitud contemplativa asumida por el sujeto y en la formulación de leyes y juicios universales; en su lugar, el autor propone un pensar histórico, interpretativo y contextual que entienda al objeto como extensión necesaria del acto de pensar y de vivir del sujeto, por lo que su actuar y conocer constituyen el mundo a la vez que éste constituye al sujeto. Por lo cual, entender al sujeto como un ángulo necesariamente colocado e histórico no tiene la pretensión de formar juicios universales que agoten la movilidad del sujeto y del mundo, más bien propende por la conformación de juicios estructurados por niveles contenidos que hagan posible la potenciación del conocimiento desde el mismo uso del lenguaje.

Por último, parece adecuado cerrar con una de las frases más dicientes que el autor consigna en el libro "Pensar y poder":

Debemos asumir todos los días el desafío de los espacios inacabados, en cuyos marcos el sujeto refuerza su identidad. Pero tomar conciencia de que ésta puede impedir la posibilidad de asombrarse si el sujeto no asume "pensar la resistencia”, por lo que tenemos que incorporar al problema epistémicometodológico lo que es propio de lo histórico-existencial del quehacer científico." (Zemelman, 2012, p. 93)

\section{Referencias}

Zemelman, H. (2007). El ángel de la historia: determinación y autonomía de la condición humana. Barcelona, ESP: Anthropos.

Zemelman, H. (2010). Sujeto y Subjetividad: la problemática de las alternativas como construcción posible. Polis, Revista de la Universidad Bolivariana, 9(27) 355-366. Recuperado de http://journals.openedition.org/polis/943

Zemelman, H. (2012). Pensar y poder: Razonar y gramática del pensar histórico. Chiapas, México: Siglo XXI Editores. 
JUAN DAVID ZABALA SANDOVAL

http://orcid.org/0000-0001-8999-4053

Profesor del programa de psicologia de la Universidad de Ibagué. Estudiante de Doctorado en Ciencias Sociales de la Universidad de Chile. Psicólogo y Magister en Educación. Actualmente trabajando acerca de la constitución de identidades en excombatientes del conflicto armado interno y en construcción de subjetividad marginal em habitantes de calle.

Dirección: Carrera 22 - Calle 67, Barrio Ambalá, Ibagué, Tolima, Colombia. E-mail: juan.zabala@,unibague.edu.co

\section{Histórico}

Sumisión: 19/02/2018

Revisión: 30/10/2019

Aceptación: 30/03/2020 